\title{
INVESTIGATING THE REVERSE LINK ERLANG TRAFFIC CAPACITY OF A POWER CONTROLLED WIRELESS LOCAL LOOP CDMA SYSTEM
}

\author{
Nawal El-Fishawy \\ Faculty of Electronic Engineering, Department of Electronics and \\ Electrical Communications, Menouf, Egypt \\ E.mail:nelfishawy@hotmail.com
}

\section{Essam Sourour}

Faculty of Engineering, Department of Electrical Communications, Alexandria, Egypt

E.mail: sourour@ieee.org

\author{
Ahmed Salah \\ Telecom Egypt, Cairo, Egypt \\ E.mail:ahm_sa0@yahoo.com
}

(Received January 5, 2006 Accepted March 14, 2006)

\begin{abstract}
In this paper, the reverse link Erlang traffic capacity of a power controlled CDMA based Wireless Local Loop (WLL) voice system equipped with high gain directional antennas at either the base station or users' houses is investigated. It is shown that the Erlang traffic capacity of CDMA based WLL system is several times that of mobile cellular CDMA system and conventional multiple access systems, such as FDMA and TDMA based systems. Finally the study of Telecom Egypt WLL CDMA2000-1xRTT network is examined as a case study.
\end{abstract}

\section{INTRODUCTION}

In a few years it is anticipated that the majority of telephone services in the world will be based on wireless access. Wireless Local Loop (WLL) is an emerging technology, deploys fixed-to-fixed radio link to connect subscribers in remote locations to the Public Switching Telephone Network (PSTN) using radio signals as a substitute for copper lines for all or part of the connection between the subscriber and the switch [1], [2]. It is believed to be a fast and cost-effective means to provide local phone service more cheaply and quickly in sparsely populated rural areas and third worlds countries than through copper based access telephone networks. Since WLL is a fixed-to-fixed radio communication system, narrowbeam antennas can be employed at both the base station and subscriber's side at high spot in a nonobstructive environment so that the propagation between base station and house is very close to free space propagation. This gives the WLL system many inherent advantages over the traditional cellular system, such as bigger coverage area, low power, reduce interference, higher capacity, 
no fast fading, and no handoff. For any multiuser communication system, the measure of its economic usefulness is the Erlang capacity, rather than the maximum number of users which can be served at one time [3]. Erlang capacity of a system can be defined as the average traffic load in terms of average number of users requesting service, and resulting in blocking probability restricted by a certain degree of service. Blocking probability is the probability that a new user will find all channels busy and hence be denied service if the system is blocked call cleared system or allowed to join a queue waiting for service if the system is delay system. In FDMA and TDMA based multiuser communication systems the number of available frequency and time slots are the limiting factors for the number of users. Blocking occurs when the number of users exceeds the number of available frequency or time slots. In CDMA the system is designed to tolerate a certain level of interference so the number of users is not strictly limited. Admission control algorithms monitor the interference and rejects new users if necessary. Blocking in CDMA systems will be defined to occur when the total interference plus thermal noise power to thermal noise power exceeds a given level $1 / \eta$ (where $\eta=0.1$ corresponding to $10 \mathrm{~dB}$ ).

The rest of paper is organized as follows. In section II, the system model including the propagation model is described. Section III presents the analytical model for both conventional multiple access systems, such as FDMA and TDMA based systems, and CDMA based WLL system and the performance analysis is of each system is discussed. Section V presents the simulation results. Next, in section VI the case study (Telecom Egypt WLL CDMA2000-1xRTT network for providing local phone service to Egyptian rural areas and villages) is introduced. Finally, section VII concludes the paper.

\section{SYSTEM MODEL}

The system model used in this analysis is a multicell CDMA system consisting of 5-tier of cells that are assumed to be hexagonal in shape and identical in size which is normalized to unity. For every cell there are $N$ users randomly distributed around each base station within a range equal to cell size. The geometry of the system model can be represented as shown in Fig.1. Where $r_{i k}^{(k)}$ is the distance from the $i_{k}$-th user in the $k$-th cell and its base station $B S_{k}, r_{i k}^{(o)}$ is the distance from $i_{k}$-th user and the desired user's base station $B S_{o}$, and $d_{k}$ is the distance between the interfering cell's base station $B S_{k}$ and the desired user's base station $B S_{o}$. We assume that the base station of both WLL CDMA system and mobile cellular CDMA system uses multielemnt adaptive antenna array to form narrow beams toward each user. In mobile cellular CDMA system, no antenna arrays are considered for the user terminal due to practical difficulties in implementing such a concept. On the other side, in WLL CDMA system the fixed-tofixed radio link allows high gain directional antennas to be equipped at users' houses. Since CDMA system is an interference-limited system in which the link performance depends on the ability of receiver to detect a signal in the presence of interference [5]. Each base station in the system receives co-channel interference consists of intra-cell interference coming from users in the desired user's cell and inter-cell interference 


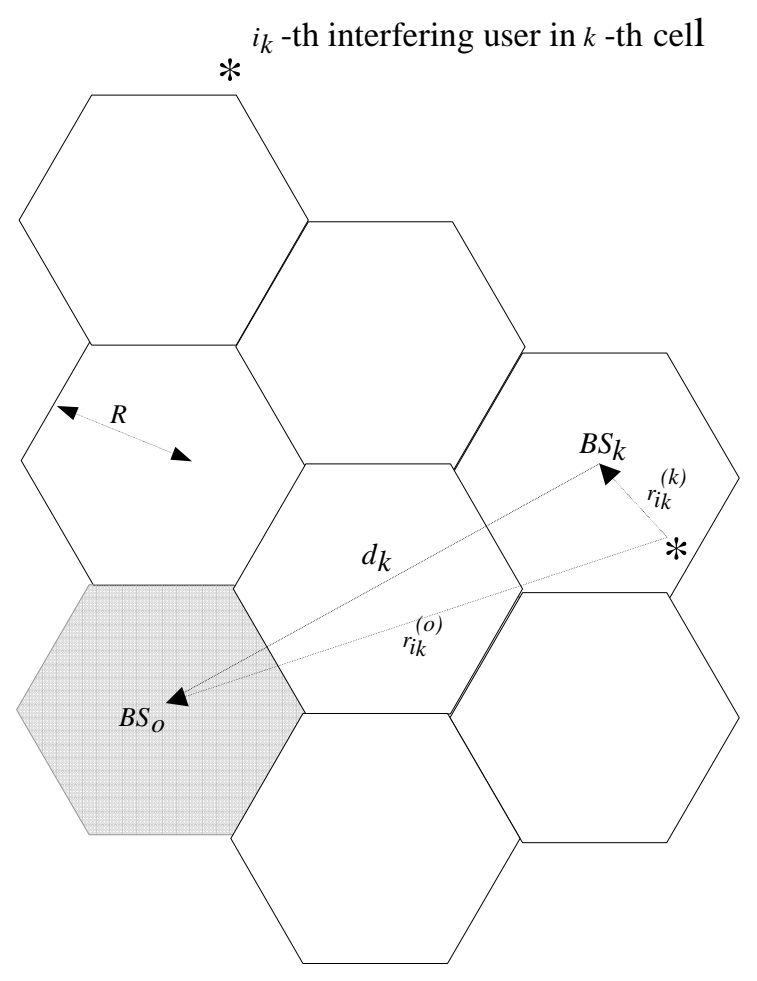

Fig. 1: Geometry of the system model for interference evaluation.

coming from users in neighboring cells. Clearly the use of multielement adaptive antenna array at each base station and directional antennas at users' houses to form directional beams is a good way to reduce interference power and hence increasing system capacity. To be able to form such beams, the base station needs to have knowledge of directional of arrival (DOA) of the desired user's signal. For beamforming a uniform linear array with $\ell$ interelement spacing and $M$ antenna elements is considered. The $3 d B$-beam width (width of the main lobe) of the array is taken to be the angel between first nulls on either side of the main lobe (i.e. twice the angel between the main lobe maximum and first null). For a broadside array the width of main lobe is given by

$$
2 \Delta \phi=2 \cdot \sin ^{-1}\left(\frac{\lambda}{\mathrm{M} \cdot \ell}\right)
$$

Assuming a narrow band signal model, the $M \times 1$ received signal by the antenna array at the desired user's base station $B S_{o}$ can be expressed as

$$
\mathrm{X}(\mathrm{t})=\sum_{\mathrm{i}_{\mathrm{O}=1}}^{\mathrm{N}} \alpha_{\mathrm{i}_{\mathrm{o}}} \sqrt{\mathrm{S}_{\mathrm{i}_{\mathrm{o}}}} \mathrm{d}_{\mathrm{i}_{\mathrm{o}}}\left(\mathrm{t}-\tau_{\mathrm{i}_{\mathrm{o}}}\right) \mathrm{a}_{\mathrm{i}_{\mathrm{o}}}\left(\theta_{\mathrm{i}_{\mathrm{o}}}\right)+\sum_{\mathrm{k}=1}^{\mathrm{k}} \sum_{\mathrm{i}_{\mathrm{k}}=1}^{\mathrm{N}} \alpha_{\mathrm{i}_{\mathrm{k}}} \sqrt{\mathrm{I}_{\mathrm{ik}}} \mathrm{d}_{\mathrm{i}_{\mathrm{k}}}\left(\mathrm{t}-\tau_{\mathrm{i}_{\mathrm{k}}}\right) \mathrm{a}_{\mathrm{ik}}\left(\theta_{\mathrm{ik}}\right)+\mathrm{N}(\mathrm{t})
$$

where $s_{i_{o}}$ is the power received at the base station $B S_{o}$ from the $i_{o}$-th user in the home cell, $I_{i_{k}}$ is the interference power received at base station $B S_{o}$ from $i_{k}$-th interfering 
users in $k$-th neighboring cell, $d_{i_{k}}(t)$ is the PN-code modulated bit stream of the $i_{k}$-th user with processing gain $G, \alpha_{i_{k}}$ is the speech activity factor of the $i_{k}$-th user, $N(t)$ is the thermal noise vector, and $a\left(\theta_{i_{k}}\right)$ is the array response vector of $i_{k}$-th user's signal arriving at DOA angel $\theta_{i_{k}}, a\left(\theta_{i_{k}}\right)$ depends on its DOA angel $\theta_{i_{k}}$ and on parameters common to all users these parameters are number of array elements $M$, interelement spacing $\ell$, and wave length $\lambda$ where

$$
a_{i_{k}}\left(\theta_{i_{k}}\right)=\left[\begin{array}{c}
1 \\
e^{j \frac{2 \pi}{\lambda} \ell \sin \left(\theta_{i_{k}}\right)} \\
e^{j \frac{2 \pi}{\lambda} 2 \ell \sin \left(\theta_{i_{k}}\right)} \\
\vdots \\
e^{j \frac{2 \pi}{\lambda}(M-1) \ell \sin \left(\theta_{i_{k}}\right)}
\end{array}\right]
$$

For spreading spectrum of CDMA system using direct sequence method (DS), spreading and dispreading done through a process called bitstream multiplication where in the case of uplink the user's information bit stream is multiplied by its PNcode (spreaded) to produce PN-code modulated bit stream. For bitstream multiplication process, user's information bitstream and its $\mathrm{PN}$-code are assumed to be i.i.d. binary random variables taking values \pm 1 with equal probability. As shown in Fig. 2, the output of each array element is despreaded (correlated) by the desired user's PN-code to yield one sample vector per bit and then filtered out using integration and dump filter to produce post correlation signal vector $e(l)$ [6], [7]. For the desired user, let $\alpha_{o}, S_{o}, d_{o}, a\left(\theta_{o}\right)$, and $e_{o}(l)$ be the speech activity factor, power received at $B S_{o}$, $\mathrm{PN}$-code modulated bit stream, array resonance vector, and the post correlated signal vector respectively. The post correlated signal vector for the desired user's $l$-th bit $e_{o}(l)$ is then multiplied by complex weights vector $W$

$$
\mathrm{W}=\left[\begin{array}{c}
\mathrm{w}_{1} \\
\mathrm{w}_{2} \\
\mathrm{~W}_{3} \\
\vdots \\
\mathrm{W}_{\mathrm{M}}
\end{array}\right]
$$

The weights vector is determined by some beamforming algorithm to yield optimum signal-to-interference $(S I R)$ power ratio, the output of beamformer is given by 


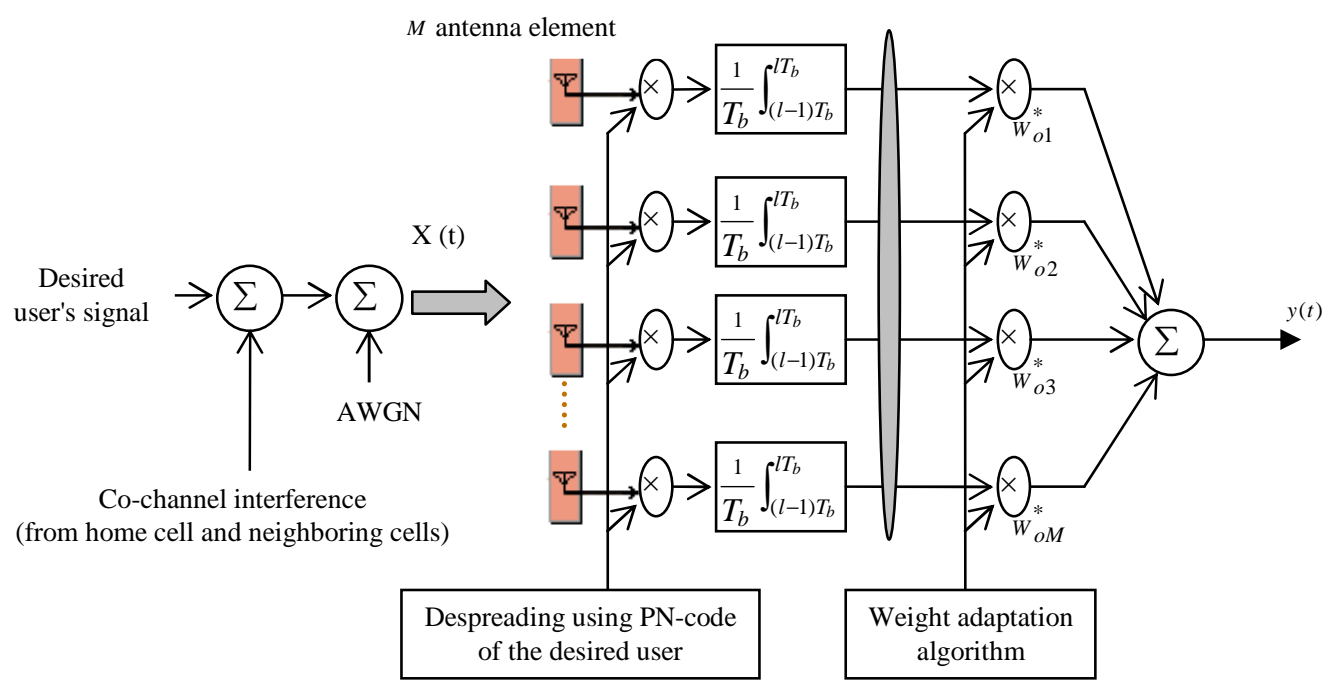

Fig. 2: Received signal model at the antenna array.

$$
y(t)=w^{H} e_{o}(1)
$$

where $(\bullet)^{H}$ stands for Hermitian transpose operator. In order to estimate the desired user's signal [8], we need to estimate its array response vector $a_{O}\left(\theta_{O}\right)$ and using this estimate to adapt weights of the beamformer. Maximum gain of the antenna array will be obtained if $W_{O}=a_{O}\left(\theta_{O}\right)$, where $W_{O}$ is the weights vector adapted for the desired user. The signal-to-interference plus noise power spectral density $(p s d)$ ratio is given

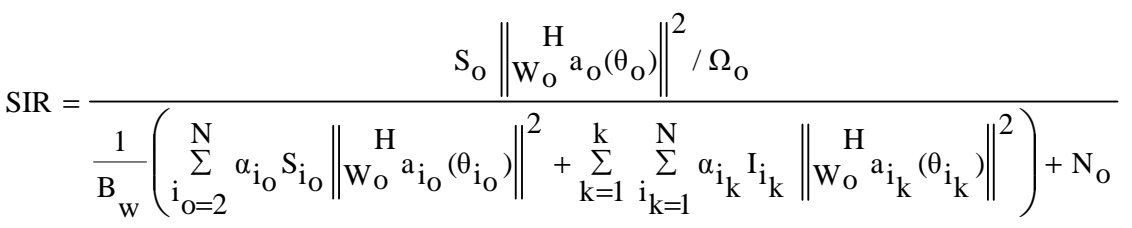

$$
\begin{aligned}
& \mathrm{S}_{\mathrm{o}}\left\|\mathrm{W}_{\mathrm{o}} \mathrm{a}_{\mathrm{o}}\left(\theta_{\mathrm{o}}\right)\right\|^{2} \mathrm{G}_{\mathrm{o}} \\
& =\overline{\left(\sum_{i_{0}=2}^{N} \alpha_{i_{o}} S_{i_{o}}\left\|w_{0}^{H} a_{i_{o}}\left(\theta_{i_{o}}\right)\right\|^{2}+\sum_{k=1}^{k} \sum_{i_{k=1}^{N}}^{N} \alpha_{i_{k}} I_{i_{k}}\left\|w_{o}^{H} a_{i_{k}}\left(\theta_{i_{k}}\right)\right\|^{2}\right)+N_{o} B_{w}}
\end{aligned}
$$

Where $N_{o}$ is the thermal noise power spectral density. And $G_{o}$ is the processing gain of the desired user which equal to $B_{w} / \Omega_{o}$ where $\Omega_{o}$ is the desired user's information bit rate, $B_{w}$ is the spreading bandwidth.

\section{A. Propagation Model}

The signal propagation through radio channel is generally modeled as a product of three components; one is the path loss between the user and the base station which is 
inversely proportional to the distance of separation between the user and the base station raised to a power between 2 and 5, with a typical value of 4 representing path loss exponent which is dependent upon propagation characteristic, the second is a random variable with log-normal distribution representing slow variation of the mean of the received signal power due to shadowing, and the third representing directional antenna gain. Hence the total propagation path loss for a user at given distance $r$ from a base station can be written as

$$
\operatorname{PL}(r, \mu)=\left(\frac{1}{r}\right)^{\gamma} \cdot 10^{(\mu / 10)} \cdot G
$$

where $\mu$ is a Gaussian random variable representing the log-normal shadowing process $\gamma$ is the path loss exponent, and $\mathrm{G}$ is the directional antenna gain. Due to shadowing local mean of the signal power fluctuates around the area mean with lognormal distribution of standard deviation $\delta$ which varies between 6 and 12 depending on the degree of shadowing. We assume that the fast fading which is largely due to multipath propagation does not affect the average signal level. Our model uses an ideal radiation antenna pattern given by

$$
\mathrm{G}(\psi)= \begin{cases}1, & -\Delta \phi \leq \Psi \leq \Delta \phi \\ 0, & \text { otherwise }\end{cases}
$$

where $\psi$ is the devotion angel from the beam pattern symmetrical axis.

\section{PERFORMANCE ANALYSIS OF THE WLL CDMA SYSTEM AND CONVENTIONAL MULTIPLE ACCESS SYSTEMS}

\section{A. Analytical Model and Performance Analysis of WLL CDMA System}

Unlike mobile cellular system, the fixed-to-fixed radio link of CDMA based WLL system enables high gain directional antennas to be equipped at users' houses. As a result, the interference coming from users in other cells gets significantly lower; this is because not every house from another cell causes interference into the desired user's cell (home cell). Only those whose transmitting antennas cover the home cell base station are interferers, this interference reduction leads to a relative increase in Erlang traffic capacity of WLL CDMA system over mobile cellular CDMA system and other existing FDMA and TDMA based systems. In order to compute the reverse link Erlang traffic capacity of WLL CDMA system we need to compute both intra-cell and intercell interference powers received at the desired user's base station. Assuming perfect power control at the each base station, signals transmitted from all users in the desired user's cell will arrive at base station $B S_{o}$ with the same power level; in other words, $s_{i_{o}}=S$ for all values of $i_{o}\left(\right.$ i.e., $\left.2 \leq i_{o} \leq N\right)$. In this case the intra-cell interference power spectral density is given by

$$
\mathrm{I}_{\text {intra }}=\frac{1}{\mathrm{~B}_{\mathrm{w}}} \cdot \sum_{\mathrm{i}_{\mathrm{O}}=2}^{\mathrm{N}} \mathrm{S} \alpha_{\mathrm{i}_{\mathrm{O}}} .
$$


In the $k$-th neighboring cell the area of interfering houses whose transmitting antennas cover the home cell base station are denoted as the interference area, which is shown as a shadowed area in Fig. 3.

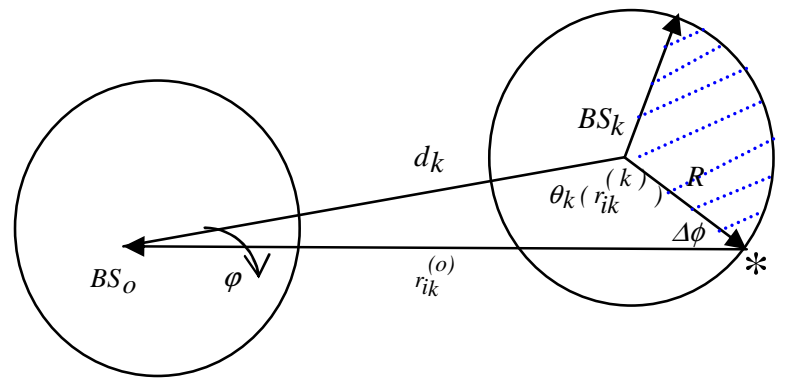

Fig. 3: Interference area from a single cell (interference user at the boundary of the interference area).

Since the fixed-to-fixed radio link of WLL CDMA system enables directional antennas to be placed at a high spot in a nonobstructive environment the signal propagation through the radio channel is closed to that in free space, so that the received signal power falls off with distance according to a second power law (path loss exponent equal 2). Due to perfect power at each base station the received power at base station $B S_{k}$ of a $k$-th interfering cell from $i_{k}$-th house is $S$, then its transmitting power will be

$$
\mathrm{ST}=\mathrm{S}\left(\mathrm{r}_{\mathrm{ik}}(\mathrm{k})\right)^{2}
$$

The interference power received at the desired user's base station $B S_{o}$ from $i_{k}$-th house is then given by:

$$
\mathrm{I}_{\mathrm{i}}\left(\mathrm{r}_{\mathrm{i}}{ }_{\mathrm{k}}^{(\mathrm{k})}, \mathrm{r}_{\mathrm{i}}^{(\mathrm{o})}\right)=\mathrm{ST}\left(\frac{1}{\mathrm{r}_{\mathrm{ik}}^{(\mathrm{o})}}\right)^{2}=\mathrm{S}\left(\frac{\mathrm{r}_{\mathrm{ik}}^{(\mathrm{k})}}{\mathrm{r}_{\mathrm{ik}}^{(\mathrm{o})}}\right)^{2}
$$

The total interference power received at base station $B S_{o}$ from the $k$-th interfering cell calculated by either taking the summation of the interference power received from each interfering house in the interference area or by integrating the total interference power over the interference region [8].

$$
\begin{aligned}
& I_{k}=2 \int_{0}^{R} \int_{\theta_{k}\left(r_{i k}^{(k)}\right)}^{\pi} \alpha_{i_{k}} \rho S \cdot\left(\frac{r_{i k}^{(k)}}{r_{i k}^{(o)}}\right)^{2} d \theta \cdot r_{i k}^{(k)} \mathrm{dr}_{i k}^{(k)}
\end{aligned}
$$

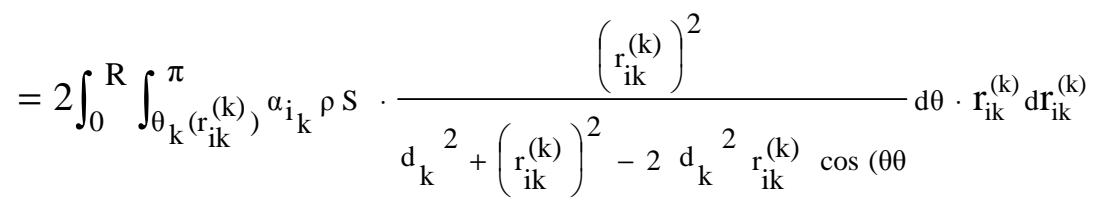


where house density $\rho$ is equal to $N /\left(\pi \cdot R^{2}\right)$ where $R$ is the cell radius. The interference area boundary $\theta_{k}\left(r_{i k}^{(k)}\right)$ can be calculated as follows:

$$
\begin{aligned}
\theta_{\mathrm{k}}\left(\mathrm{r}_{\mathrm{ik}}^{(\mathrm{k})}\right) & =\pi-\Delta \phi-\varphi \\
& =\pi-\Delta \phi-\sin ^{-1}\left(\frac{\mathrm{r}_{\mathrm{ik}}^{(\mathrm{k})} \cdot \sin (\Delta \phi)}{\mathrm{d}_{\mathrm{k}}}\right) .
\end{aligned}
$$

The total other cell interference (inter-cell interference) received by the home cell base station $B S_{O}$ is given by

$$
\mathrm{I}_{\text {int er }}=\sum_{\mathrm{k}=1}^{\mathrm{k}} \mathrm{I}_{\mathrm{k}}
$$

where $I_{k}$ is given in (12), now we define the total relative interference factor $f$ as

$$
\begin{aligned}
\mathrm{f} & =\frac{\text { inter }- \text { cell interfererce from all other cells }\left(\mathrm{I}_{\text {inter }}\right)}{\text { intra }- \text { cell interferere }\left(\mathrm{I}_{\text {intra }}\right)} \\
& =\frac{\sum_{\mathrm{k}=1}^{\mathrm{k}} \mathrm{I}_{\mathrm{k}}}{\sum_{\mathrm{N}}^{\mathrm{N}} \mathrm{S} \alpha_{\mathrm{i}_{\mathrm{o}}}}
\end{aligned}
$$

Using (6), (11), (9) the signal-to-interference plus noise power spectral density (psd) ratio for WLL CDMA system can be expressed as

$$
\begin{aligned}
& (\mathrm{SIR})_{\mathrm{w}}=\frac{\mathrm{S}\left\|\mathrm{W}_{\mathrm{o}}^{\mathrm{H}} \mathrm{a}_{\mathrm{o}}\left(\theta_{\mathrm{o}}\right)\right\|^{2} \mathrm{G}_{\mathrm{o}}}{\left(\sum_{\mathrm{i}_{\mathrm{o}=2}}^{\mathrm{N}} \alpha_{\mathrm{i}_{\mathrm{o}}} \mathrm{S}\left\|\mathrm{W}_{\mathrm{o}}^{\mathrm{H}} \mathrm{a}_{\mathrm{i}_{\mathrm{o}}}\left(\theta_{\mathrm{i}_{\mathrm{o}}}\right)\right\|^{2}+\sum_{\mathrm{k}=1}^{\mathrm{k}} \sum_{\mathrm{i}_{\mathrm{k}=1}}^{\bar{N}} \alpha_{\mathrm{i}_{\mathrm{k}}} \mathrm{S}\left(\frac{\mathrm{r}_{\mathrm{ik}}^{(\mathrm{k})}}{\mathrm{r}_{\mathrm{ik}}^{(\mathrm{o})}}\right)^{2}\left\|\mathrm{~W}_{\mathrm{o}}^{\mathrm{H}} \mathrm{a}_{\mathrm{i}_{\mathrm{k}}}\left(\theta_{\mathrm{i}_{\mathrm{k}}}\right)\right\|^{2}\right)+\mathrm{N}_{\mathrm{o}} \mathrm{B}_{\mathrm{w}}} \\
& =\frac{\left\|\mathrm{W}_{\mathrm{o}}^{\mathrm{H}} \mathrm{a}_{\mathrm{o}}\left(\theta_{\mathrm{o}}\right)\right\|^{2} \mathrm{G}_{\mathrm{o}}}{\left(\sum_{\mathrm{i}_{\mathrm{o}=2}}^{\mathrm{N}} \alpha_{\mathrm{i}_{\mathrm{o}}}\left\|\mathrm{W}_{\mathrm{o}}^{\mathrm{H}} \mathrm{a}_{\mathrm{i}_{\mathrm{o}}}\left(\theta_{\mathrm{i}_{\mathrm{o}}}\right)\right\|^{2}+\sum_{\mathrm{k}=1}^{\mathrm{k}} \sum_{\mathrm{i}_{\mathrm{k}=1}}^{\bar{N}} \alpha_{\mathrm{i}_{\mathrm{k}}}\left(\frac{\mathrm{r}_{\mathrm{ik}}^{(\mathrm{k})}}{\mathrm{r}_{\mathrm{ik}}^{(\mathrm{o})}}\right)^{2}\left\|\mathrm{~W}_{\mathrm{o}}^{\mathrm{H}} \mathrm{a}_{\mathrm{i}_{\mathrm{k}}}\left(\theta_{\mathrm{i}_{\mathrm{k}}}\right)\right\|^{2}\right)+\delta_{\mathrm{n}}^{2}}
\end{aligned}
$$

Where $\bar{N}$ is the number of houses in the interference area of the $k$-th interference cell, $\delta_{n}^{2}$ is the thermal noise-to-signal power ratio which equal to $N_{o} B_{w} / S$ (normalized 
thermal noise power). Since Maximum gain of the antenna array will be obtained if $W_{o}=a_{o}\left(\theta_{O}\right)$, assume that $a_{i k}\left(\theta_{i k}\right)^{*} a_{i k}\left(\theta_{i k}\right)=1$.

To achieve good quality in a CDMA system, the total normalized interference power plus normalized thermal noise power divided by normalized thermal noise power should be lower than a given level $1 / \eta$ (where $\eta=0.1$ corresponding to $10 \mathrm{~dB}$ ).

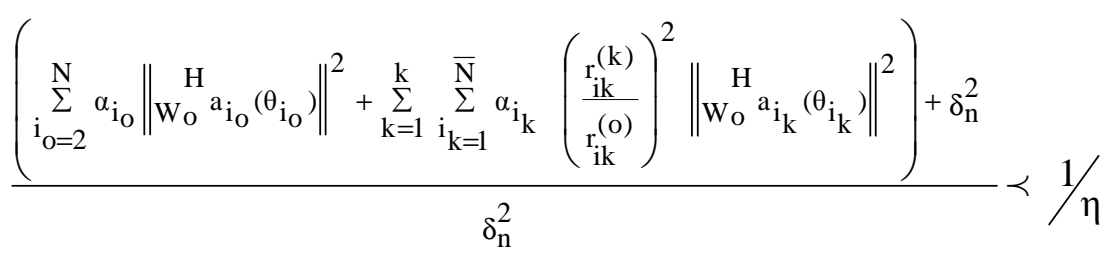

If we introduce a new parameter $\mathrm{z}$ where

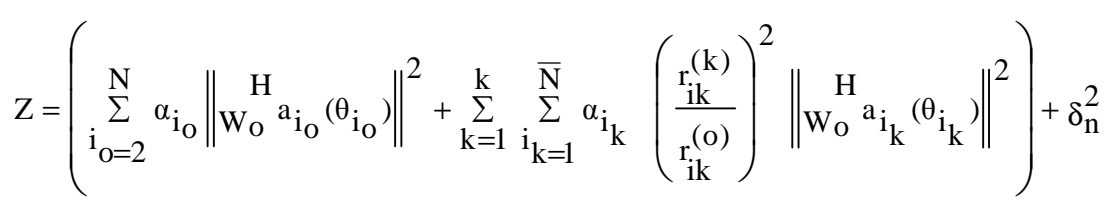

In order to get an expression for the good service condition we can use equations (16), (17), and (18) to form equation (19)

$$
\mathrm{Z} \prec \frac{\mathrm{G}_{\mathrm{O}}}{(\mathrm{SIR})_{\mathrm{W}}}(1-\eta)
$$

The blocking probability can be expressed as

$$
\mathrm{P}_{\mathrm{bl}}=\mathrm{P}_{\mathrm{r}}\left(\mathrm{Z} \succ \frac{\mathrm{G}_{\mathrm{O}}}{(\mathrm{SIR})_{\mathrm{W}}}(1-\eta)\right)
$$

If we define a new parameter $A$,

$$
A=\frac{G_{0}}{(\operatorname{SIR})_{W}}(1-\eta)
$$

Since $\mathrm{Z}$ is a sum of binomial distributed random variables we can use a central limit theorem approximation. Thus the blocking probability can be written as

$$
\mathrm{P}_{\mathrm{bl}}=\mathrm{Q}\left(\frac{\mathrm{A}-\mathrm{E}(\mathrm{Z})}{\sqrt{\operatorname{VAR}(\mathrm{Z})}}\right)
$$

Here we need to find the expected value and standard deviation of the random variable $\mathrm{Z}$.

In order to compute the Erlang capacity of multi-cell WLL CDMA system we model the number of active users $N$ by a Poisson distribution

$$
\mathrm{P}_{\mathrm{N}}=\frac{(\lambda / \mu)^{\mathrm{N}}}{\mathrm{N} !} \mathrm{e}^{-(\lambda / \mu)}
$$


Where $\lambda / \mu$ is the offered average traffic measured in Erlangs, called occupancy parameter, $\lambda$ is the total average call arrival rate from the entire population of users and $1 / \mu$ is the average time per call (call duration). The mean value of $P_{N}$ is $\lambda / \mu$ and its standard deviation is $\lambda / \mu$.The call service time $\tau$ per user is assumed to be exponentially distributed so the probability that $\tau$ exceeds $T$ is given by

$$
\mathrm{P}_{\mathrm{r}}(\tau \succ \mathrm{T})=\mathrm{e}^{-\mu \mathrm{T}}
$$

In [3] Viterbi has derived expressions for the expected value and standard deviation for Z. An expression for the blocking probability in a multi-cell CDMA WLL system with perfect power control at each base station is

$$
P_{b l}=Q\left(\frac{A-\frac{\alpha \lambda}{\mu}(1+f)}{\sqrt{\frac{\alpha \lambda}{\mu}(1+f)}}\right)
$$

where $f$ is the total relative interference factor, the factor $\alpha \lambda / \mu$ represents the interference comes from home cell, and $\alpha \lambda f / \mu$ represents total interference comes from other cells.

\section{B. Conventional Multiple Access Systems}

In conventional multiple access systems, such as FDMA and TDMA, traffic channels are allocated to users as long as there are available free channels. Blocking occur if the number of users $N$ requesting service exceeds the number of available traffic channels. The Erlang B-formula gives a relationship between the average traffic load in terms of average number of users requesting service and blocking probability where

$$
\mathrm{P}_{\mathrm{bl}}=\frac{(\lambda / \mu)^{\mathrm{N}} / \mathrm{N} !}{\sum_{\mathrm{k}=0}^{\mathrm{N}}(\lambda / \mu)^{\mathrm{k}} / \mathrm{k} !}
$$

Table 1: Conventional multiple access systems.

\begin{tabular}{|l|c|c|c|}
\hline \multicolumn{1}{|c|}{ System } & AMPS & D-AMPS & GSM \\
\hline Access method & FDMA & TDMA & TDMA \\
\hline Duplex method & FDD & FDD & FDD \\
\hline Carrier separation & $30 \mathrm{kHz}$ & $30 \mathrm{kHz}$ & $200 \mathrm{kHz}$ \\
\hline Frequency reuse & 7 & 7 & 7 \\
\hline Number of carriers in $12.5 \mathrm{MHz}$ & 416 & 416 & 62 \\
\hline Time slots /carrier & 1 & 3 & 8 \\
\hline Number of traffic channels per cell & 57 & 171 & 67 \\
\hline Erlang traffic per cell at 1\% blocking & 44.221 & 151.743 & 53.353 \\
\hline
\end{tabular}




\section{SIMULATION AND NUMERICAL RESULTS}

In all of our simulations and numerical results, we considered only 5-tiers of interfering cells each of cell size normalized to unity. We assume that the speech activity factor $\alpha$ is .6. In our simulations it is assumed that the beamwidth of multielement antenna array was taken to be slightly more than that computed by (1) to account for the interference energy picked up through the side lobes of the array pattern; where as the number of array elements increases the gain of antenna increases and more side lobes occur. We assume that for adequate performance the link requirement for WLL based CDMA system $(S I R)_{w}$ is $5 d B$ and for mobile cellular CDMA system is $7 d B$ [9]. For WLL CDMA system typical values of relative interference factor $f$ is plotted in Fig. 4 as a function of house antenna beamwidth and number of array element $M$ using (15). From the figure, it is clear that the relative interference factor $f$ decreases as the number of array element $M$ increases and house antenna beamwidth becomes narrower.

Consider base station alone uses multielement antenna arrays with different number of elements $M$, and interelement spacing $\ell$ equal to $\lambda / 2$ to form narrow beams toward the desired users, house antenna is considered to be omni-directional. Results for blocking probability are obtained by simulations based on (20); the results are summarized in Fig. 5. From the figure it is clear that by using multielement antenna array at base station, many fold increase in Erlang traffic capacity of WLL CDMA system can be obtained. Table 2 presents the traffic capacity in Erlang per cell at 1\% blocking probability.

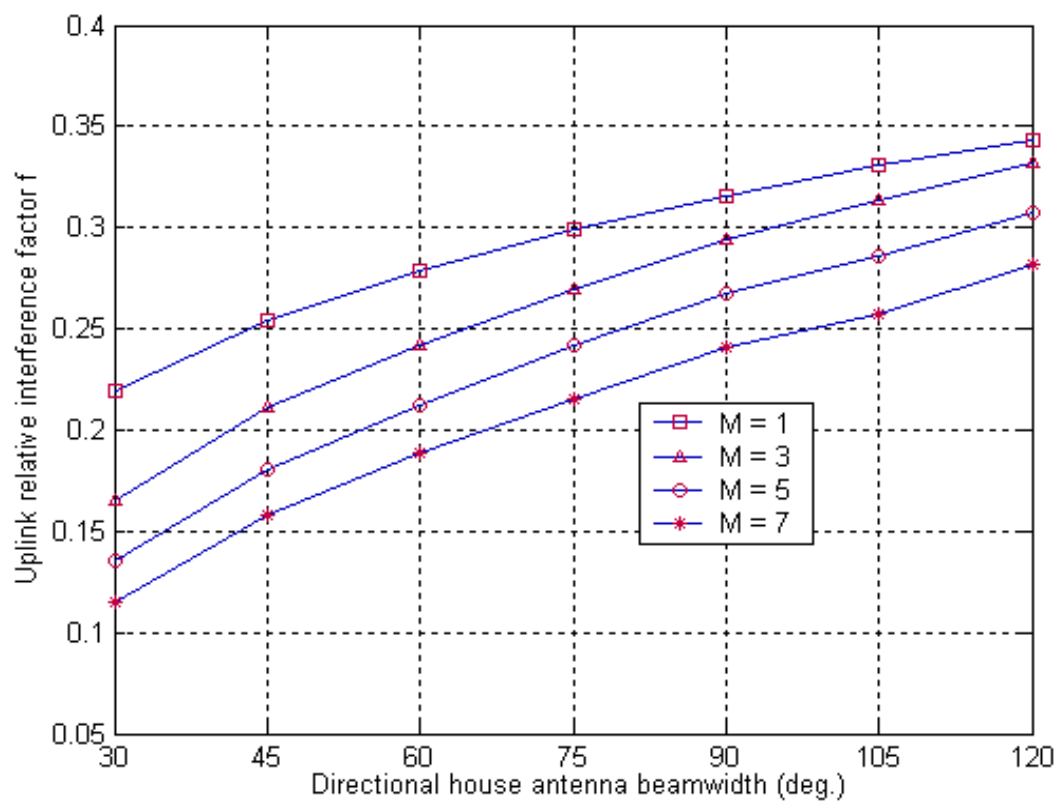

Fig. 4: WLL CDMA uplink relative interference factor $f$ versus beam width of directional house antenna with different array element number $M$ at base station, $\left(\gamma=2, G_{o}=128\right.$, $\alpha=6)$. 


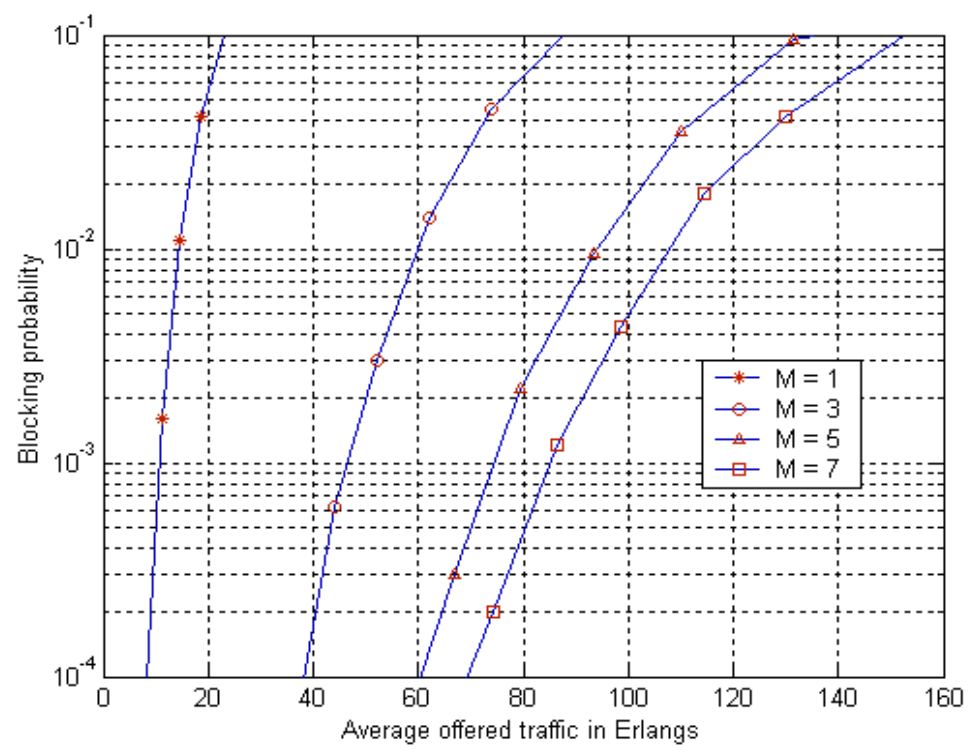

Fig. 5: WLL CDMA uplink Erlang traffic capacity per cell versus blocking probability; with different array element number $M$ at base station; house antenna is omnidirectional, $\left(\gamma=2, G_{o}=128, \alpha=.6\right)$

Table 2: Erlang traffic capacity per cell at $1 \%$ blocking.

\begin{tabular}{|c|c|c|c|c|}
\hline \multirow{2}{*}{ House antenna } & \multicolumn{4}{|c|}{ Omni-directional } \\
\hline Number of array element at base station & $M=1$ & $M=3$ & $M=5$ & $M=7$ \\
\hline Erlang traffic per cell & 14 & 60 & 94 & 108 \\
\hline
\end{tabular}

In Fig. 6, the effect of both directional house antenna beamwidth and number of array element at base station in the reverse link Erlang traffic capacity of WLL CDMA at 1\% blocking is investigated. From the results, it is clear that Erlang traffic capacity can be increased with narrower house antenna beamwidth. Specially, when $M$ is 7 nearly 40 Erlang can be added in each cell by decreasing house antenna beamwidth from 120 to 30 degree. More significant improvement can be achieved if antenna array is equipped at the base station. For example, the Erlang traffic capacity of WLL CDMA system can be about 6 to 7 times larger if omni-directional antenna at base station $(M=1)$ is replaced by antenna array with 7 array elements. That is because both intra-cell and inter-cell interference power can be suppressed effectively by using antenna arrays at base station to from narrow beams, while the directional house antenna at the subscriber side can only reduce the inter-cell interference power.

Figure 7 shows the relative increase in Erlang traffic capacity attained in WLL CDAM system over mobile cellular CDMA system and conventional multiple access systems. The base station for both WLL and mobile cellular CDMA systems uses multi-element antenna array with 7 array elements. For mobile cellular CDMA system we assume 
that the standard deviation of Gaussian random variable which represents power loss variation due to log-normal shadowing is $4 d B$. From the results it is clear that, in all cases the relative increase in Erlang traffic capacity increases as the beam width of house antenna becomes narrower where these directional antennas with narrow beams

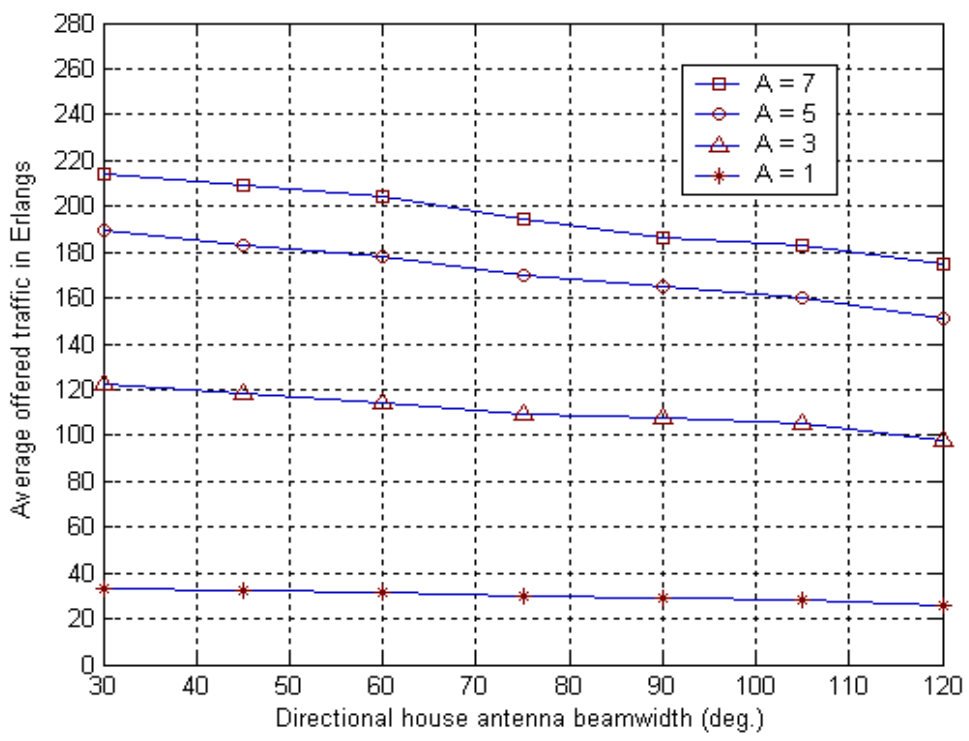

Fig. 6: WLL CDMA uplink Erlang traffic capacity per cell at $1 \%$ blocking versus beamwidth of directional house antenna with different array element number $M$ at base station, $\left(\gamma=2, G_{O}=128, \alpha=.6\right)$.

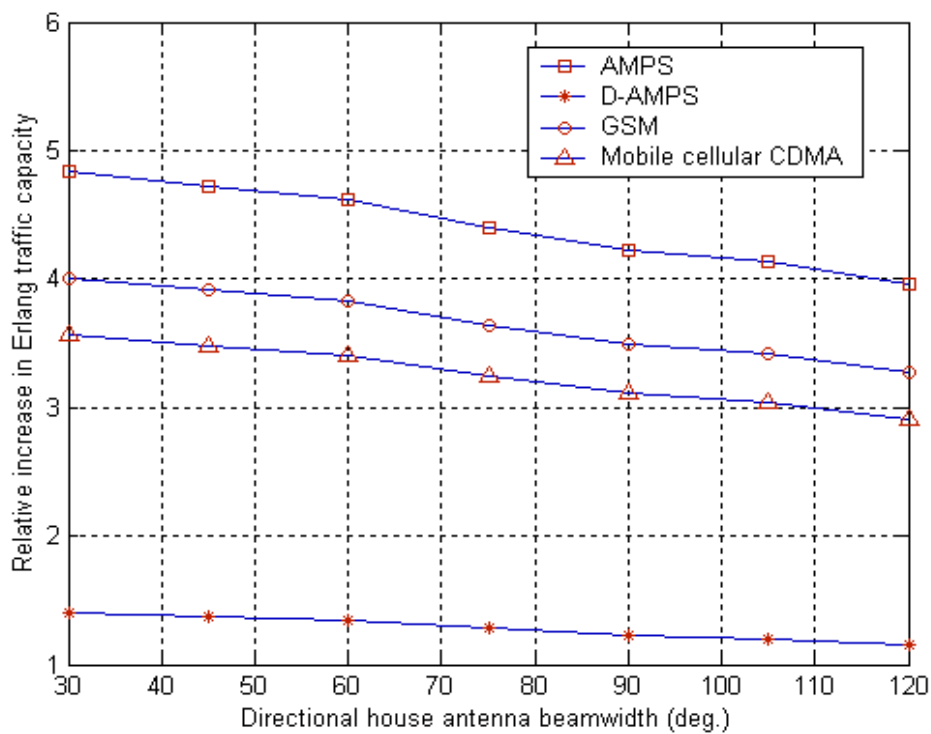

Fig. 7: Relative increase in Erlang traffic capacity attained in WLL CDAM system over mobile cellular CDMA system and conventional multiple access systems versus beamwidth of directional house antenna, $\left(\gamma=2, G_{o}=128, M=7, \alpha=.6\right)$. 
reduce other-cell interference power. This interference reduction in addition to fading reduction (nonfading fixed-to-fixed radio link of WLL CDMA system) both leads to a relative increase in Erlang traffic capacity for WLL CDMA system over mobile cellular CDMA system and conventional multiple access systems.

\section{CASE STUDY TELECOM EGYPT WLL CDMA2000-1XRTT NETWORK FOR PROVIDING THE LOCAL PHONE SERVICE TO THE EGYPTIAN RURAL AREAS AND VILLAGES}

\section{A. Introduction}

One of the most important challenges for Telecom Egypt as a fixed service provider in Egypt is increasing teledensity in Egyptian rural areas and villages (number of telephone lines per 100 person in these areas). For Egypt villages are either allocated in a scattered way within a certain area or allocated cascaded along a certain road or along the Nile River. They may be connected with copper-based access network or not connect, and the subscriber density in these areas may be low or relatively high. Since Wireless Local Loop (WLL) technologies are to a large extent well-established and technically proven solutions for providing the local phone services to rural and sparsely populated areas. The fixed service providers decided to serve these areas using WLL networks based on several technologies including [1]:

1- Technologies based on cordless mobile radio standard (e.g., DECT, PHS, CT-2);

2- Technologies based on cellular mobile radio standard (e.g., GSM, IS-95 CDMA, CDMA2000);

3- Proprietary WLL technologies (e.g., Lucent Airloop, Nortel Proximity I).

The fixed service providers have to choose the most suitable technology taking into account the following requirements:

1- Most cost effective solution overall; since the requirement for low cost is imperative especially in developing and low income regions where only the economically most feasible solution can create a competitive advantage;

2- High scalability for continuous growth and network expansion;

3- Standardized roadmap for network evolution.

Ignoring any one of these requirements will make it difficult to ensure competitive telecommunications infrastructure in the region.

\section{B. Objective and Implementation Details of Telecom Egypt WLL CDMA Project}

Telecom Egypt has decided to serve Egyptian rural areas and villages using WLL network based on cellular technology (CDMA2000).The objective of this project is to provide the basic telephony services, community development, internet services, and small business support services. Telecom Egypt has tendered for implementation of this WLL CDMA project for different technology manufacturing companies, the best and more economic offers are chosen. Two Chinese companies Huawei and ZTE won this tendered and have shared the implementation. Telecom Egypt has provided the total cost for implementation of this WLL CDMA project and didn't get either a partnership or any aid (commercial launch of the project $2^{\text {nd }}$ quarter 2005) [10]. In addition to the efforts of Telecom Egypt in increasing teledensity in Egyptian rural 
areas, the ministry of telecommunications \& IT represented by its National Telecommunication Regulatory Authority (NTRA) decided to release its Universal Services box for telecommunications project with an initial capital cost of L.E 50.000.000. The purpose of this project is increasing teleaccessability in rural areas (number of telephone lines per 100 houses in theses areas) [11].

\section{Infrastructure and Regulatory of the Project}

In Telecom Egypt WLL CDMA project, the pre-existing telecommunication infrastructure facilities are used as much as possible. For economical purpose, most of the base transceiver stations (BTSs) are located and implemented above the existing local exchanges; these BTSs are powered from main existing AC power of the local exchanges and are connected to the base station controller (BSC) through the existing transmission media as fiber rings, and microwave links. On the other hand some BTSs are located apart from the local exchanges depending on coverage purposes; with distance ranges from 20 to $100 \mathrm{~km}$; the places of these BTs are chosen to fulfill the AC power requirement and security procedures. The connections between these BTSs and BSC are new microwave links. Telecom Egypt has got a license from the NTRA in Egypt for radio propagation frequency bands. The license assigned three radio frequency carriers for uplink in the radio frequency range $824-849 \mathrm{MHz}$ and another three for downlink in the frequency range 869-894 MHz. The NTRA has specified licenses conditions; that Telecom Egypt has accepted them; these licensing conditions can be summarized as follows:

- Serving villages in suburban and rural areas.

- Serving the highways.

- Using the specified frequencies only.

Tables 3 and $\mathbf{4}$ show the data sheet of the WLL CDMA network implemented by the Chinese company ZTE. This network dedicated to serve the Nile Valley and its surrounding areas; the most developed and populated areas in Egypt [12]. Corresponding to our simulation, Figs. 8 and $\mathbf{9}$ show the Erlang traffic capacity per cell as a function of blocking probability for the home cell Kafr El Shekh which uses one sector base station and the home cell Tanta which uses three sectors base station respectively and each is surrounding by 29 neighboring (interfering) cells. Table 5 present the traffic capacity in Erlang per cell at 1\% blocking probability.

For Kafr El Shekh home cell, the simulation results show that, depending on the house antenna beamwidth, between 16 and 34 Erlangs per cell may carried at 1\% blocking. For 16 Erlang of traffic, the Erlang-B formula estimates the number of active users sharing the same CDMA physical channel to be 26 users per cell. For 34 Erlangs of traffic the number of users estimated to be 46 . For Tanta home cell, between 48 to 91 Erlangs per cell may carried at $1 \%$ blocking depending on the house antenna beamwidth. The number of active users estimated to be 62 users per cell for 48 Erlangs of traffic and 108 users for 91 Erlangs of traffic. By decreasing the house antenna beamwidth, the interference received at the home cell is reduced and hence significant increase in Erlang traffic capacity. The effect of sectorization in Erlang traffic capacity is observed, where the Erlang capacity of CDMA system with sectorization increased by a factor equal to number of sectors this is because the interference is effectively reduced by the same amount. 
Table 3: Data sheet of Telecom Egypt WLL CDMA network (Tanta is the home cell).

\begin{tabular}{|c|c|c|c|c|c|}
\hline \multirow{2}{*}{ cell } & \multirow{2}{*}{ Neighboring cells } & \multirow{2}{*}{ dk } & \multirow{2}{*}{$\begin{array}{l}\text { Cell } \\
\text { radius } \\
\mathbf{R}\end{array}$} & \multirow{2}{*}{$\begin{array}{c}\text { Antenna } \\
\text { height }\end{array}$} & \multirow{2}{*}{\begin{tabular}{|c|} 
Sectorization \\
Sectors/cell
\end{tabular}} \\
\hline & & & & & \\
\hline \multirow{29}{*}{ Tanta } & Shabour & $18 \mathrm{Km}$ & $15 \mathrm{Km}$ & $50 \mathrm{~m}$ & 2 \\
\hline & Dalanget & $42 \mathrm{Km}$ & $15 \mathrm{Km}$ & $50 \mathrm{~m}$ & 2 \\
\hline & Hosh Essa & $65 \mathrm{Km}$ & $10 \mathrm{Km}$ & $35 \mathrm{~m}$ & 2 \\
\hline & Najaa El Ruz & $85 \mathrm{Km}$ & $10 \mathrm{Km}$ & $50 \mathrm{~m}$ & Omni \\
\hline & Amrya Exchange & $110 \mathrm{Km}$ & $18 \mathrm{Km}$ & $70 \mathrm{~m}$ & 1 \\
\hline & Damnhour & $53 \mathrm{Km}$ & $16 \mathrm{Km}$ & $60 \mathrm{~m}$ & 2 \\
\hline & Disuq & $46 \mathrm{Km}$ & $15 \mathrm{Km}$ & $50 \mathrm{~m}$ & 2 \\
\hline & Kafr El Shekh & $35 \mathrm{Km}$ & $15 \mathrm{Km}$ & $45 \mathrm{~m}$ & 1 \\
\hline & Kafr Eldwar & $85 \mathrm{Km}$ & $15 \mathrm{Km}$ & $45 \mathrm{~m}$ & 2 \\
\hline & Ezbat El Jadidah & $76 \mathrm{Km}$ & $15 \mathrm{Km}$ & $50 \mathrm{~m}$ & 2 \\
\hline & Sidi Salim & $53 \mathrm{Km}$ & $12 \mathrm{Km}$ & $40 \mathrm{~m}$ & 2 \\
\hline & Alhamoul & $55 \mathrm{Km}$ & $15 \mathrm{Km}$ & $45 \mathrm{~m}$ & 1 \\
\hline & Kafr El Jarydah & $50 \mathrm{Km}$ & $15 \mathrm{Km}$ & $50 \mathrm{~m}$ & 2 \\
\hline & Tamalay & $36 \mathrm{Km}$ & $15 \mathrm{Km}$ & $50 \mathrm{~m}$ & 2 \\
\hline & Sobk EI Dahak & $40 \mathrm{Km}$ & $15 \mathrm{Km}$ & $50 \mathrm{~m}$ & 2 \\
\hline & Bani Helal & $50 \mathrm{Km}$ & $15 \mathrm{Km}$ & $50 \mathrm{~m}$ & 2 \\
\hline & Kafr Shokr & $34 \mathrm{Km}$ & $15 \mathrm{Km}$ & $50 \mathrm{~m}$ & 3 \\
\hline & Al Alqmah & $60 \mathrm{Km}$ & $15 \mathrm{Km}$ & $50 \mathrm{~m}$ & 3 \\
\hline & Zifta & $23 \mathrm{Km}$ & $12 \mathrm{Km}$ & $42 \mathrm{~m}$ & 1 \\
\hline & Aga & $30 \mathrm{Km}$ & $15 \mathrm{Km}$ & $50 \mathrm{~m}$ & 2 \\
\hline & Al Mugatah & $54 \mathrm{Km}$ & $15 \mathrm{Km}$ & $50 \mathrm{~m}$ & 1 \\
\hline & El Sofiah & $73 \mathrm{Km}$ & $15 \mathrm{Km}$ & $50 \mathrm{~m}$ & 2 \\
\hline & Al Husaniah & $83 \mathrm{Km}$ & $15 \mathrm{Km}$ & $45 \mathrm{~m}$ & 2 \\
\hline & Qaryet Tarak Bn Zyad & $100 \mathrm{Km}$ & $15 \mathrm{Km}$ & $50 \mathrm{~m}$ & 2 \\
\hline & Dikirnis & $62 \mathrm{Km}$ & $15 \mathrm{Km}$ & $50 \mathrm{~m}$ & 2 \\
\hline & Al Manzlah & $92 \mathrm{Km}$ & $15 \mathrm{Km}$ & $50 \mathrm{~m}$ & 3 \\
\hline & Meit Abu Ghalb & $82 \mathrm{Km}$ & $15 \mathrm{Km}$ & $50 \mathrm{~m}$ & 2 \\
\hline & Natron Exchange & $75 \mathrm{Km}$ & $18 \mathrm{Km}$ & $70 \mathrm{~m}$ & 1 \\
\hline & 26k Exchange & $76 \mathrm{Km}$ & $16 \mathrm{Km}$ & $60 \mathrm{~m}$ & 1 \\
\hline
\end{tabular}


Table 4: Data sheet of Telecom Egypt WLL CDMA network (Kafr El Shekh is the home cell).

\begin{tabular}{|c|c|c|c|c|c|}
\hline \multirow{2}{*}{ Home cell } & \multirow{2}{*}{ Neighboring cells } & \multirow{2}{*}{$\mathbf{d k}$} & \multirow{2}{*}{$\begin{array}{c}\text { Cell } \\
\text { radius } \\
\mathbf{R} \\
\end{array}$} & \multirow{2}{*}{$\begin{array}{c}\text { Antenna } \\
\text { height }\end{array}$} & \multirow{2}{*}{$\begin{array}{l}\text { Sectorization } \\
\text { Sectors/cell }\end{array}$} \\
\hline & & & & & \\
\hline \multirow{29}{*}{$\begin{array}{l}\text { Kafr El } \\
\text { Shekh }\end{array}$} & Shabour & $33 \mathrm{Km}$ & $15 \mathrm{Km}$ & $50 \mathrm{~m}$ & 2 \\
\hline & Dalanget & $46 \mathrm{Km}$ & $15 \mathrm{Km}$ & $50 \mathrm{~m}$ & 2 \\
\hline & Hosh Essa & $61 \mathrm{Km}$ & $10 \mathrm{Km}$ & $35 \mathrm{~m}$ & 2 \\
\hline & Najaa EI Ruz & $82 \mathrm{Km}$ & $10 \mathrm{Km}$ & $50 \mathrm{~m}$ & Omni \\
\hline & Amrya Exchange & $102 \mathrm{Km}$ & $18 \mathrm{Km}$ & $70 \mathrm{~m}$ & 1 \\
\hline & Damnhour & $42 \mathrm{Km}$ & $16 \mathrm{Km}$ & $60 \mathrm{~m}$ & 2 \\
\hline & Disuq & $25 \mathrm{Km}$ & $15 \mathrm{Km}$ & $50 \mathrm{~m}$ & 2 \\
\hline & Tanta & $35 \mathrm{Km}$ & $15 \mathrm{Km}$ & $70 \mathrm{~m}$ & 3 \\
\hline & Kafr Eldwar & $72 \mathrm{Km}$ & $15 \mathrm{Km}$ & $45 \mathrm{~m}$ & 2 \\
\hline & Ezbat El Jadidah & $53 \mathrm{Km}$ & $15 \mathrm{Km}$ & $50 \mathrm{~m}$ & 2 \\
\hline & Sidi Salim & $22 \mathrm{Km}$ & $12 \mathrm{Km}$ & $40 \mathrm{~m}$ & 2 \\
\hline & Alhamoul & $28 \mathrm{Km}$ & $15 \mathrm{Km}$ & $45 \mathrm{~m}$ & 1 \\
\hline & Kafr El Jarydah & $33 \mathrm{Km}$ & $15 \mathrm{Km}$ & $50 \mathrm{~m}$ & 2 \\
\hline & Tamalay & $66 \mathrm{Km}$ & $15 \mathrm{Km}$ & $50 \mathrm{~m}$ & 2 \\
\hline & Sobk El Dahak & $74 \mathrm{Km}$ & $15 \mathrm{Km}$ & $50 \mathrm{~m}$ & 2 \\
\hline & Bani Helal & $78 \mathrm{Km}$ & $15 \mathrm{Km}$ & $50 \mathrm{~m}$ & 2 \\
\hline & Kafr Shokr & $65 \mathrm{Km}$ & $15 \mathrm{Km}$ & $50 \mathrm{~m}$ & 3 \\
\hline & Al Alqmah & $80 \mathrm{Km}$ & $15 \mathrm{Km}$ & $50 \mathrm{~m}$ & 3 \\
\hline & Zifta & $49 \mathrm{Km}$ & $12 \mathrm{Km}$ & $42 \mathrm{~m}$ & 1 \\
\hline & Aga & $36 \mathrm{Km}$ & $15 \mathrm{Km}$ & $50 \mathrm{~m}$ & 2 \\
\hline & Al Mugatah & $64 \mathrm{Km}$ & $15 \mathrm{Km}$ & $50 \mathrm{~m}$ & 1 \\
\hline & El Sofiah & $80 \mathrm{Km}$ & $15 \mathrm{Km}$ & $50 \mathrm{~m}$ & 2 \\
\hline & Al Husaniah & $92 \mathrm{Km}$ & $15 \mathrm{Km}$ & $45 \mathrm{~m}$ & 2 \\
\hline & Qaryet Tarak Bn Zyad & $105 \mathrm{Km}$ & $15 \mathrm{Km}$ & $50 \mathrm{~m}$ & 2 \\
\hline & Dikirnis & $60 \mathrm{Km}$ & $15 \mathrm{Km}$ & $50 \mathrm{~m}$ & 2 \\
\hline & Al Manzlah & $90 \mathrm{Km}$ & $15 \mathrm{Km}$ & $50 \mathrm{~m}$ & 3 \\
\hline & Meit Abu Ghalb & $72 \mathrm{Km}$ & $15 \mathrm{Km}$ & $50 \mathrm{~m}$ & 2 \\
\hline & Natron Exchange & $95 \mathrm{Km}$ & $18 \mathrm{Km}$ & $70 \mathrm{~m}$ & 1 \\
\hline & 26k Exchange & $110 \mathrm{Km}$ & $16 \mathrm{Km}$ & $60 \mathrm{~m}$ & 1 \\
\hline
\end{tabular}




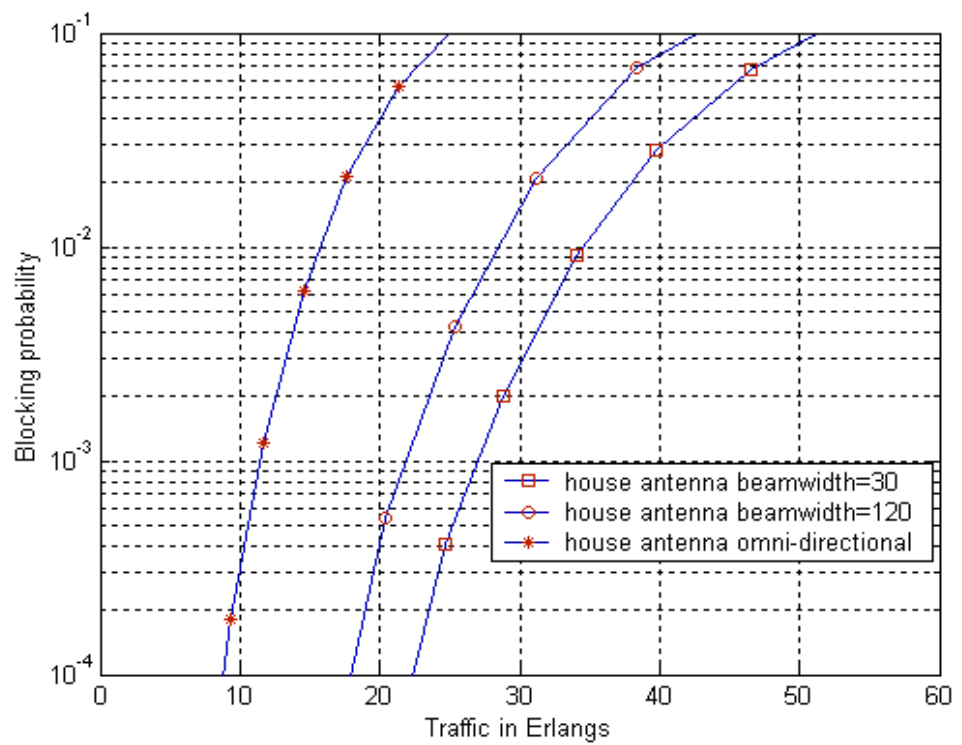

Fig. 8: Erlang traffic per cell versus blocking probability for Kafr El Shekeh home cell; $\left(\gamma=2, G_{o}=128, \alpha=.6\right)$, one sector base station.

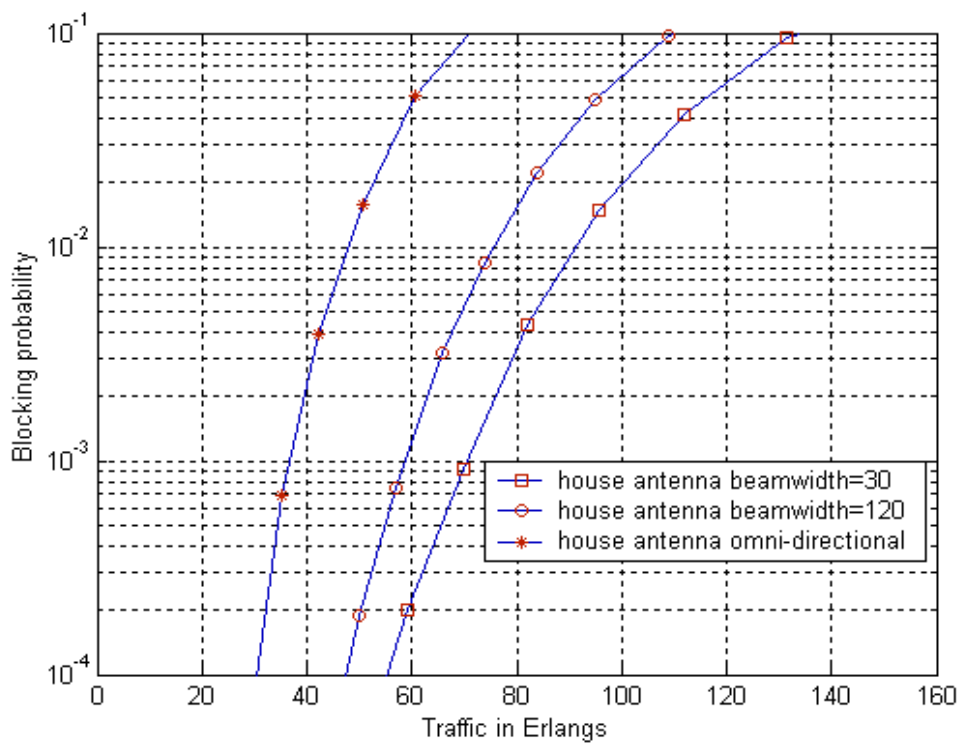

Fig. 9: Erlang traffic per cell versus blocking probability for Tanta home cell; $\left(\gamma=2, G_{O}=128, \alpha=.6\right)$, three sectors base station.

Table 5: Erlang traffic capacity per cell for each home cell at $1 \%$ blocking.

\begin{tabular}{|c|c|c|c|}
\hline \multirow{2}{*}{ Home cell } & \multicolumn{3}{|c|}{ House Antenna Beamwidth } \\
\cline { 2 - 4 } & Omni-directional & 120 deg. & 30 deg. \\
\hline Kafr El Shekh & 16 & 28 & 34 \\
\hline Tanta & 48 & 75 & 91 \\
\hline
\end{tabular}




\section{CONCLUSIONS}

In this article, we have studied the reverse link Erlang traffic capacity of a power controlled WLL CDMA voice system equipped with high gain directional antennas at either the base station or users' houses. Our analytical and simulation results showed that for WLL CDMA system several fold Erlang traffic capacity improvement can be achieved when antenna arrays incorporated at the base stations, and additional capacity improvement can be achieved by using narrow beam antennas at users' houses. This is because of the interference reduction using narrow beam antennas. We also observed that there is a relative increase in Erlang traffic capacity attained in WLL CDMA system over mobile cellular CDMA system and conventional multiple access systems such as FDMA and TDMA based. Finally we apply the study to Telecom Egypt WLL CDMA2000-1xRTT network as a case study.

\section{REFERENCES}

[1] W. Webb, Introduction to wireless local loop, Artech House, 1998.

[2] A. Noerpel, Yi-B. Lin, "Wireless local loop: architecture, technologies and services," IEEE Personal Commun., pp. 74-80, June 1998.

[3] A. J. Viterbi, A. M. Viterbi "Eralng capacity of a power controlled CDMA system," IEEE J. On selected areas in commun, Vol. 11, No. 6, pp.892-900, Aug 1993.

[4] V. Garg, IS-95 CDMA and cdma2000: cellular/pcs systems implementation, Prentice Hall PTR, 2000.

[5] A. Naguib, A. Paulraj, and T. Kailash, "Capacity improvement with basestation antenna arrays in cellular CDMA," IEEE Trans. Vehic.Tech., Vol. 43, No. 3, Aug. 1994.

[6] S. Moshavi, " Multi-user detection for DS-CDMA communications," IEEE Commun. Mag., pp.124-136, Oct.1996.

[7] S. Bellofiore, J. Foutz, C. Balanis, and A. Spanias "Smart-antenna system for mobile communication networks," IEEE Antenna's and propagation mag, Vol. 44, No. 4, pp. 106-114, Aug 2002.

[8] D. Lee and C. Xu, "The effect of narraowbeam antenna and multiple tiers on system capacity in CDMA wireless local loop," IEEE Commun. Mag., pp.110114, Sept. 1997.

[9] W. Lee, "Spectrum and technology of a wireless local loop system," IEEE Personal Commun, pp.49-54, Feb.1998.

[10] http:// www.telecomegypt.com.eg

[11] http://www.ntra.gov.eg

[12] http://www.cdg.org 


\section{دراسة السعة الكلية لخطوط الاتصال الخلفية لنظام الولوج المتعدد لأقسام الثفرة (CDMA) ذات القدرة المنظمة والمطبق الثلى على النظام الحلقي اللاسلكي}

في هذا البحث تم حساب السعة الكلية لخطوط الاتصال الخلفية لنظام الولوج المتعدد لأقسام

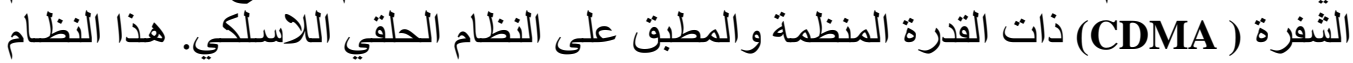

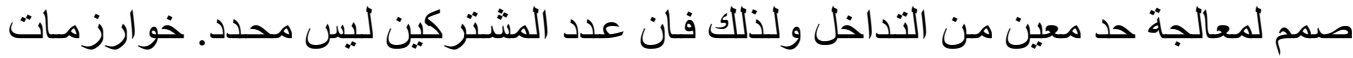

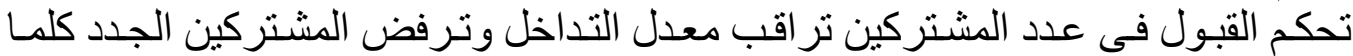

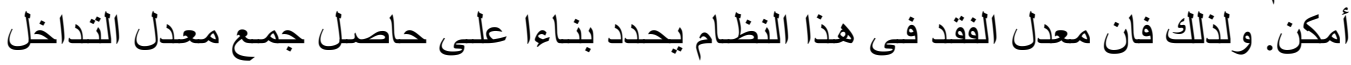

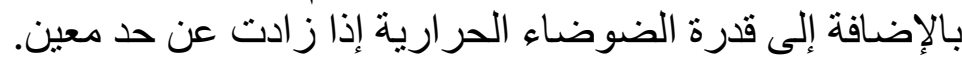

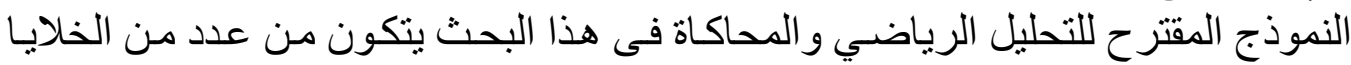

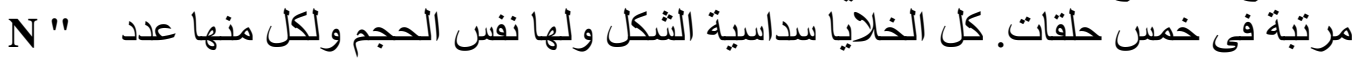

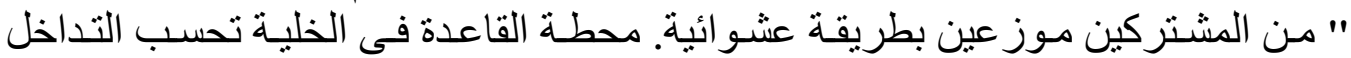

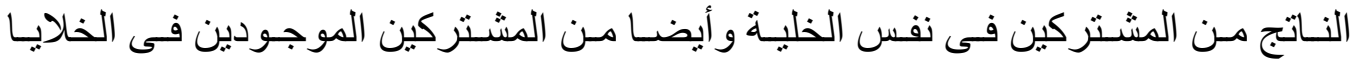

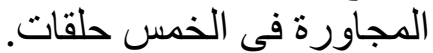

FDMA,

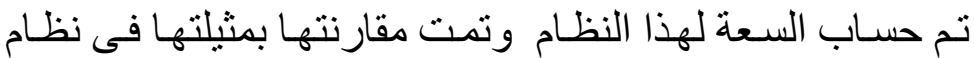
و و أيضا ال CDMA

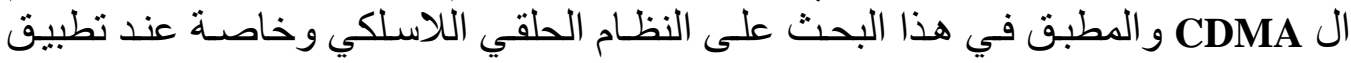

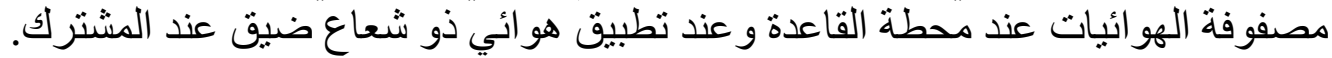

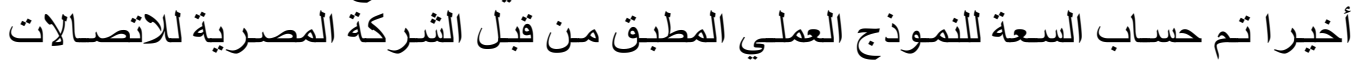
CDMA2000-1XRTT المطبق فى الدلتا. 